\title{
Indirect Sliding Mode Control of Power Converters Via Double Integral Sliding Surface
}

\author{
Siew-Chong Tan, Member, IEEE, Y. M. Lai, Member, IEEE, and Chi K. Tse, Fellow, IEEE
}

\begin{abstract}
The steady-state regulation error in power converters that use the conventional hysteresis-modulation-based sliding mode controller can be suppressed through the incorporation of an additional integral term of the state variables into the controller. However, it is found that with the indirect type of sliding mode controller (derived based on the equivalent control approach), the same approach of integral sliding mode control is ineffective in alleviating the converter's steady-state error. Moreover, the error increases as the converter's switching frequency decreases. This paper presents an in-depth study of the phenomenon and offers a solution to the problem. Specifically, it is proposed that an additional double-integral term of the controlled variables to be adopted for constructing the sliding surface of indirect sliding mode controllers. Simulation and experimental results are provided for verification.
\end{abstract}

Index Terms-Double-integral sliding mode (SM), nonlinear controller, power converters, pulsewidth modulation (PWM), sliding mode (SM) control.

\section{INTRODUCTION}

$\mathbf{T}$ HE sliding mode (SM) controller is a kind of nonlinear controller which was introduced for controlling variable structure systems (VSS) [1]. Its major advantages are guaranteed stability and robustness against parameter, line, and load uncertainties [1]. Moreover, being a controller that has a high degree of flexibility in its design choices, the SM controller is relatively easy to implement as compared to other types of nonlinear controllers. Such properties make it highly suitable for control applications in nonlinear systems, including power electronics [2]-[6]. It has been repeatedly demonstrated that the SM controller is a viable solution for enhancing the control performance of power converters [7]-[34].

However, the actual practical adoption of SM controllers in power converters is often limited by two major concerns: the non-constant operating frequency of the SM controller, and the presence of steady-state error in the regulation. To address the first concern, various possible methods of fixating the switching frequency of SM controllers have been proposed. These include the use of adaptive strategies [12], [30], the incorporation of constant timing functions or circuitries [7], [9], [26], and the indirect implementation of the SM controllers [14], [29], [34]. As for the second concern, it has been widely known that the

Manuscript received March 5, 2007; revised October 22, 2007. A preliminary version of the paper was presented at the IEEE Power Electronics Specialists Conference, 2007. Recommended for publication by Associate Editor B. Fahimi.

The authors are with the Department of Electronic and Information Engineering, The Hong Kong Polytechnic University, Hong Kong (e-mail: ensctan@ polyu.edu.hk).

Digital Object Identifier 10.1109/TPEL.2007.915624 steady-state errors of SM controlled systems can be effectively suppressed through the use of an additional integral term of the state variables in the SM controller [9], [14], [19], [21], [23], [25]. This method is known as integral SM control. When incorporated, the consequence is an SM controlled system 1) with motion equation of the same order as the original system; and 2) with better robustness and regulation property than the traditional SM controlled system [1].

Interestingly, in a recent attempt to implement a type of fixed-frequency indirect SM controllers, which is based on pulsewidth-modulation (PWM), for the dc-dc converters [29], [32], [34], it is noted that the adoption of the integral sliding mode (ISM) control scheme in these controllers can reduce, but not fully alleviate the steady-state error of the converters. Our investigation shows that this is due to the imperfect steady-state error correction method of the PWM-based ISM controllers. The problem is common to all types of indirect ISM controllers derived from the equivalent control method [14], [17], [20], [29], [32], [34]. It is also found that the steady-state error increases as the converter's switching frequency decreases and that the error can be quite large at a low switching frequency.

Since increasing the order of the controller of a system generally improves the steady-state accuracy [35], we explore the possibility of alleviating the steady-state regulation error of the indirect ISM controlled converters by increasing the order of the indirect ISM controllers using an additional integral term. Hence, the objective of this paper is to present an in-depth study of the phenomenon, and to report the effectiveness of the proposed solution - the use of double-integral state variables for constructing the sliding surface of indirect SM controllers for power converters, in suppressing the steady-state error. Various aspects of the proposed solution including its design and implementation are discussed in term of the fixed-frequency PWMbased (indirect) SM controller. Simulation and experimental results are provided to validate the solution. Note that although the discussion in this paper is carried out in the context of power converters, it covers an important theoretical dimension that is applicable for general controlled systems.

\section{PRoblem IDENTIFICATION}

\section{A. Review of Hysteresis-Modulation-Based SM Controllers}

Conventional direct SM controllers based on hysteresis-modulation (HM) are implemented through the real-time computation of the state variables to generate a suitable profile of the state variable's trajectory, which is then enforced to track a desired sliding surface to the equilibrium state [1]. Since SM control can achieve order reduction, it is typically sufficient to have an SM controller of $n-1$ th order for achieving stable control of 


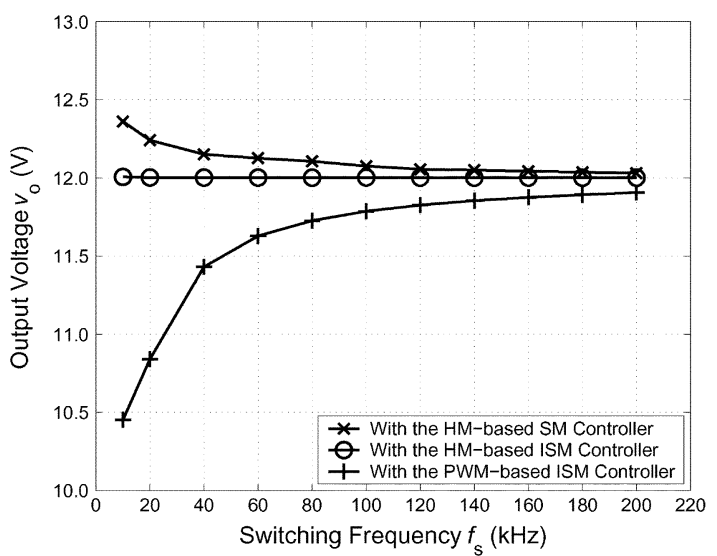

Fig. 1. Plot of steady-state output voltage $v_{o}$ against switching frequency $f_{s}$ of a $12 \mathrm{~V}$ output buck converter operating with $3 \Omega$ load under HM-based SM controller with and without integral control.

an $n$th order converter. For instance, a common form of the SM controller for an $n$th order converter adopts a switching function

$$
u= \begin{cases}u^{+} & \text {when } S>\kappa \\ u^{-} & \text {when } S<-\kappa\end{cases}
$$

where $\kappa$ is a parameter controlling the switching frequency of the system, and $S$ is the instantaneous state variable's trajectory of reduced order, which is expressed as

$$
S=\sum_{i=1}^{n-1} \alpha_{i} x_{i}
$$

where $\alpha_{i}$ for $i=1$ to $n-1$ denotes the sets of the control parameters, i.e., sliding coefficients. Under the configuration $\kappa=$ 0 , it is typically assumed in the SM control theory that the controller/converter system operates ideally at an infinite switching frequency with no steady-state error.

However, this is not true in practice. Practical non-ideality limits the switching frequency to be a finite quantity. Yet, if finite-frequency or fixed-frequency SM controllers are to be employed, the robustness and regulation properties of the converter system under the order-reduced SM controller will be deteriorated. Steady-state errors are therefore present. This can be observed from Fig. 1, which illustrates the regulation property 1 of a $12 \mathrm{~V}$ buck converter using the HM-based SM controller, the HM-based ISM controller, and the PWM-based (indirect) ISM controller, at various switching frequencies. The plot also reflects the kind of behavior expected in a converter with the HM-based SM controller, that is, the steady-state error increases as the switching frequency reduces.

A good method of suppressing these errors is to introduce an additional integral term of the state variables to the SM controller, which transforms it into an ISM controller. Since the ISM controller is of the same order as the converter, it is also known as a full-order SM controller [1]. Such an ISM controller can be obtained by modifying (2) into

$$
S=\sum_{i=1}^{n-1} \alpha_{i} x_{i}+\alpha_{n} \int \sum_{i=1}^{n-1} x_{i} d t
$$

\footnotetext{
${ }^{1}$ The presented results are obtained from computer simulation to avoid discrepancy arising from the variation of the experimental setups. They basically reflect the same characteristics as the actual experimental data of previous works.
}

where the additional state variable [as compared to (2)] is basically the integral term of all other existing state variables. Notably, it is the component $\int x_{i} d t$ which directly nullifies the steady-state errors of the respective state variables, i.e., $x_{i}$. The effect of such property can be seen in Fig. 1. It can be shown that with the HM-based ISM controller, the output voltage of the converter is maintained closely at $12 \mathrm{~V}$ with a negligible steady-state error at all switching frequencies.

However, when it comes to the indirect implementation of the ISM controller, the effectiveness of the integral control in alleviating the steady-state error deteriorates. The plot of the PWM-based ISM controller in Fig. 1 clearly demonstrates such an outcome. The following section discusses why the ISM controller succeeds in alleviating the steady-state error in the direct (HM) form, but fails in the indirect (PWM) form.

\section{B. Review of Indirect SM Controllers}

First, for implementation of any SM controller in the indirect form, the original control law must be translated [29], [34]. This is based on an approach known as the equivalent control method, which assumes the invariance conditions that during SM operation, $S=0$ and $\dot{S}=0$. From such an assumption, an equivalent control signal $u_{\mathrm{eq}}$ can be derived in terms of the respective state variables. Hence, the state variable's trajectory $S$ is indirectly formulated to track the desired sliding surface through the construction of the control signal $u_{\text {eq }}$. This makes it an indirect approach of ensuring SM operation as compared to the HM approach, which directly formulates $S$ to track the sliding surface. Note that similar to the direct SM control approach, the indirect approach must include the hitting condition which ensures the state trajectory being driven towards the sliding surface and the existence condition which ensures that the state trajectory is kept within the vicinity of the surface. Only with such constraints will the equivalent control signal derived from the original control law ensures SM operation.

To derive the equivalent control, the time differentiation of (3) is first derived, i.e.,

$$
\dot{S}=\sum_{i=1}^{n-1} \alpha_{i} \dot{x}_{i}+\alpha_{n} \sum_{i=1}^{n-1} x_{i} .
$$

Equating $\dot{S}=0$ and solving for $u_{\mathrm{eq}}$ give the general form

$$
u_{\text {eq }}=G\left(\dot{x}_{1}, \dot{x}_{2}, \ldots, \dot{x}_{n-1}, x_{1}, x_{2}, \ldots, x_{n-1}\right)
$$

where $0<u_{\text {eq }}<1$ is a function of the state variables $\dot{x}_{i}$ and $x_{i}$ for $i=1,2, \ldots, n-1$. In practice, in the case of PWM-based (indirect) SM controller implementation, the control signal $u_{\mathrm{eq}}$ is constructed through a pulsewidth modulator using a constant frequency ramp signal $v_{\text {ramp }}$ and a feedback control signal $v_{c}$, where $u_{\text {eq }}=\left(v_{c} / \hat{v}_{\text {ramp }}\right)$. Hence, both $v_{\text {ramp }}$ and $v_{c}$ are functions of the state variables $\dot{x}_{i}$ and $x_{i}$. It is important to pinpoint that the indirect construction of $S$ using the indirect approach (such as PWM) uses state variables of one time derivative order lower than the original HM-based ISM controller (see (3)). This explains why the steady-state error correction succeeds in HM-based ISM controller but fails in the indirect ISM 
controller, and why the problem is particularly severe when the switching frequency is low.

\section{Analytical Explanation for the Presence of Steady-State Error in Indirect ISM Controlled Converter}

First, in the case of the direct (HM-based) ISM controller, the sliding surface constructed comprises the integral elements of the steady-state errors, i.e., $\int x_{i} d t$ for $i=1,2, \ldots, n-1$. Recall that $\int x_{i} d t$ is a component that directly accumulates the existing steady-state errors. Hence, when the state variable's trajectory $S$ is directed to track the sliding surface to a point of equilibrium, the steady-state errors are automatically alleviated. With this process of closed-loop steady-state-error-correction feedback, the switching frequency will have little influence on the magnitude of the steady-state errors present in the HM-based ISM controlled converter.

However, for the indirect ISM controller, the variables $\int x_{i} d t$ are not explicitly reflected in the control signal [see (5)]. Instead, these integral functions are embedded in the sliding surface, of which the required error corrections are indirectly computed using the state variables $\dot{x}_{i}$ and $x_{i}$. Since there is no direct integral signal $\int x_{i} d t$ that corrects the errors of the state variables, the capability of the correction is then dependent on the accuracy of the indirect integral computation. However, such computations are open-loop processes which contain finite steady-state errors that cannot be eliminated. Hence, with steady-state errors present in the computation, steady-state errors will be present in the controlled variables. Naturally, this problem will be further aggravated if the switching frequency reduces. It is, therefore, an inefficient method of steady-state error correction and is an obvious drawback of the indirect SM controllers. This explains why the integral control scheme of the indirect ISM controller is ineffective in alleviating the steady-state errors ${ }^{2}$, especially in the low frequency range.

\section{PRoposed Solution}

It is well known that the increased order of the controller improves the steady-state accuracy of the system, but aggravates the stability problem [35]. An additional double-integral term of the state variables, i.e., $\int\left[\int x_{i} d t\right] d t$ for $i=1,2, \ldots, n-1$, is therefore introduced to correct the error of the indirect integral computation in the indirect ISM controllers. By adding an integral closed-loop to alleviate the steady-state error of the indirect integral computation, the steady-state errors of the controlled state variables are indirectly alleviated. This is the so-called double-integral (indirect) sliding mode (DISM) controller proposed in this paper. Notably, the solution is simple and straightforward. But its use in practical design is never reported and requires investigation and validation.

\footnotetext{
${ }^{2}$ In practice, it is possible to up/down lift the reference setpoint to obtain the desired output. However, it should be noted that such method of correction does not actually eliminate the steady-state errors. For operating conditions deviated from the desired point, the variation of the steady-state errors will deteriorate the regulation of the converter. To achieve a control output that follows closely to the reference setpoint for all operating conditions, it is still fundamentally required to have the feedback loop to suppress the steady-state errors for the entire range of operating conditions.
}

In its general direct HM form, the proposed DISM controller takes the switching function (1) where

$S=\sum_{i=1}^{n-1} \alpha_{i} x_{i}+\alpha_{n} \int \sum_{i=1}^{n-1} x_{i} d t$

$$
+\alpha_{n+1} \iint \sum_{i=1}^{n-1} x_{i} d t d t
$$

Clearly, this controller is of one order higher than the original converter system ${ }^{3}$. Its time differentiation

$$
\dot{S}=\sum_{i=1}^{n-1} \alpha_{i} \dot{x}_{i}+\alpha_{n} \sum_{i=1}^{n-1} x_{i}+\alpha_{n+1} \int \sum_{i=1}^{n-1} x_{i} d t
$$

is likewise an order higher than the ISM (full-order) controller (4). By solving $\dot{S}=0$, it is not difficult to see that the equivalent control $u_{\mathrm{eq}}$ is a function $G$ of the state variables $\dot{x}_{i}, x_{i}$, and $\int x_{i} d t$. Here, the additional term $\int x_{i} d t$ (as compared to ISM controller) is resulted from the double-integral term $\int\left[\int x_{i} d t\right] d t$ introduced by the DISM controller. It is interesting to see that by directly correcting the steady-state errors $x_{i}$, the original objective of introducing this component to correct the error of the indirect integral computation so that the steady-state errors of the controlled variables are alleviated is inherently met. The proposed DISM configuration easily resolves the problem of steady-state errors in indirect ISM controlled converters.

\section{APPlication of Double-InTEgral SLiding Surface to PWM-BASED TYPES OF INDIRECT SM CONTROLLERS}

This section discusses the application of the proposed solution, i.e., DISM configuration, to the PWM-based SM controllers for the voltage controlled buck converter [29] and the current controlled boost converter [32].

\section{A. Double-Integral SM Controllers}

The proposed DISM controller examples for buck converters and boost converters use the switching function $u=(1 / 2)(1+$ $\operatorname{sign}(S))$ and the sliding surface

$$
S=\alpha_{1} x_{1}+\alpha_{2} x_{2}+\alpha_{3} x_{3}+\alpha_{4} x_{4}
$$

where $u$ represents the logic state of power switch $S_{\mathrm{W}}$, and $\alpha_{1}, \alpha_{2}, \alpha_{3}$, and $\alpha_{4}$ represent the desired sliding coefficients. Also, in both examples, $C, L$, and $r_{L}$ denote the capacitance, inductance, and instantaneous load resistance respectively; $V_{\text {ref }}, v_{i}$, and $v_{o}$ denote the reference, instantaneous input, and instantaneous output voltages respectively; $\beta$ denotes the feedback network ratio; $i_{\text {ref }}, i_{L}, i_{C}$, and $i_{r}$ denote the instantaneous reference, instantaneous inductor, instantaneous capacitor, and instantaneous output currents respectively; and $\bar{u}=1-u$ is the inverse logic of $u$.

Case 1-Buck Converter: For the DISM voltage controlled buck converter, the controlled state variables are the voltage error $x_{1}$, the voltage error dynamics (or the rate of change of

\footnotetext{
${ }^{3}$ Note that the order of the controller does not correspond to the number of state variables in the controller. Even though $n-1$ state variables have been added, the actual system order of the controller increases by only one
} 
voltage error) $x_{2}$, the integral of voltage error $x_{3}$, and the double integral of the voltage error $x_{4}$, which are expressed as

$$
\left\{\begin{array}{l}
x_{1}=V_{\text {ref }}-\beta v_{o} \\
x_{2}=\dot{x_{1}} \\
x_{3}=\int x_{1} d t \\
x_{4}=\int\left(\int x_{1} d t\right) d t
\end{array} .\right.
$$

Substitution of the buck converter's behavioral models under continuous conduction mode (CCM) of operation into the time differentiation of (9) gives the dynamical model of the proposed system as

$$
\left\{\begin{array}{l}
\dot{x_{1}}=\frac{d\left[V_{\mathrm{ref}}-\beta v_{o}\right]}{d t}=-\frac{\beta}{C} i_{C} \\
\dot{x_{2}}=\frac{\beta}{r_{L} C^{2}} i_{C}-\frac{\beta v_{i}}{L C} u+\frac{\beta v_{o}}{L C} \\
\dot{x_{3}}=x_{1}=V_{\text {ref }}-\beta v_{o} \\
\dot{x_{4}}=\int x_{1} d t=\int\left(V_{\text {ref }}-\beta v_{o}\right) d t
\end{array} .\right.
$$

The equivalent control signal of the proposed DISM voltage controller when applied to the buck converter is obtained by solving $(d S / d t)=\alpha_{1} \dot{x_{1}}+\alpha_{2} \dot{x_{2}}+\alpha_{3} \dot{x_{3}}=0$ [1], which gives

$$
\begin{aligned}
u_{\text {eq }}= & \frac{\beta L}{\beta v_{i}}\left(\frac{1}{r_{L} C}-\frac{\alpha_{1}}{\alpha_{2}}\right) i_{C} \\
& +\frac{\beta v_{o}}{\beta v_{i}}+\frac{\alpha_{3}}{\alpha_{2}} \frac{L C}{\beta v_{i}}\left(V_{\text {ref }}-\beta v_{o}\right) \\
& +\frac{\alpha_{4}}{\alpha_{2}} \frac{L C}{\beta v_{i}} \int\left(V_{\text {ref }}-\beta v_{o}\right) d t
\end{aligned}
$$

where $u_{\mathrm{eq}}$ is continuous and bounded by 0 and 1 , i.e., $0<u_{\mathrm{eq}}<1$.

Case 2-Boost Converter: For the DISM current controlled boost converter, the controlled state variables are the current error $x_{1}$, the voltage error $x_{2}$, the integral of the current and the voltage errors $x_{3}$, and the double integral of the current and the voltage errors $x_{4}$, which are expressed as

$$
\left\{\begin{array}{l}
x_{1}=i_{\text {ref }}-i_{L} \\
x_{2}=V_{\text {ref }}-\beta v_{o} \\
x_{3}=\int\left[x_{1}+x_{2}\right] d t \\
x_{4}=\int\left(\int\left[x_{1}+x_{2}\right] d t\right) d t
\end{array}\right.
$$

where

$$
i_{\text {ref }}=K\left[V_{\text {ref }}-\beta v_{o}\right]
$$

and $K$ is the amplified gain of the voltage error. Substituting the boost converter's behavioral models under CCM into the time differentiation of (12) gives the dynamical model of the proposed system as

$$
\left\{\begin{array}{l}
\dot{x_{1}}=\frac{d\left[i_{\mathrm{ref}}-i_{L}\right]}{d t}=-\frac{\beta K}{C} i_{C}-\frac{v_{i}-\bar{u} v_{o}}{L} \\
\dot{x_{2}}=\frac{d\left[V_{\mathrm{ref}}-\beta v_{o}\right]}{d t}=-\frac{\beta}{C} i_{C} \\
\dot{x_{3}}=x_{1}+x_{2} \\
\dot{x_{4}}=\int\left[x_{1}+x_{2}\right] d t
\end{array} .\right.
$$

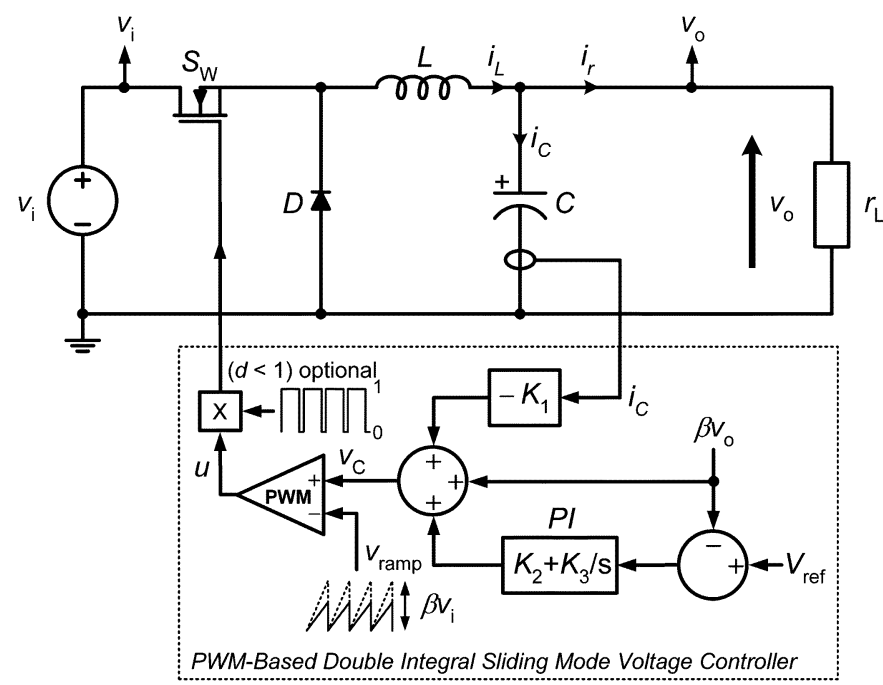

Fig. 2. Proposed pulsewidth modulation based SM voltage controller for buck converters.

Using the same approach, the equivalent control signal of the proposed DISM current controller for the boost converter is derived as

$$
\begin{aligned}
u_{\text {eq }}= & 1-\frac{\beta L}{C v_{o}}\left(K+\frac{\alpha_{2}}{\alpha_{1}}\right) i_{C}-\frac{v_{i}}{v_{o}}+\frac{\alpha_{3} L}{\alpha_{1} v_{o}}\left(V_{\text {ref }}-\beta v_{o}\right) \\
& +\frac{\alpha_{3} L}{\alpha_{1} v_{o}}\left[K\left(V_{\text {ref }}-\beta v_{o}\right)-i_{L}\right] \\
& +\frac{\alpha_{4} L}{\alpha_{1} v_{o}} \int\left(V_{\text {ref }}-\beta v_{o}\right) d t \\
& +\frac{\alpha_{4} L}{\alpha_{1} v_{o}} \int\left[K\left(V_{\text {ref }}-\beta v_{o}\right)-i_{L}\right] d t
\end{aligned}
$$

where $u_{\mathrm{eq}}$ is continuous and bounded between 0 and 1 .

\section{B. Architecture of Proposed DISM Controllers in PWM Form}

For implementation of indirect SM controller in PWM form, a set of equation comprising a control signal $v_{c}$ and a ramp signal $v_{\text {ramp }}$ with peak magnitude $\hat{v}_{\text {ramp }}$ must be derived using the indirect SM control technique [29].

Case 1-Buck Converter: In PWM form, the proposed DISM voltage controller for the buck converter inherits the expression (16), shown at the bottom of the page, where

$$
\begin{aligned}
& K_{1}=\beta L\left(\frac{\alpha_{1}}{\alpha_{2}}-\frac{1}{r_{L} C}\right) ; \quad K_{2}=\frac{\alpha_{3}}{\alpha_{2}} L C ; \text { and } \\
& K_{3}=\frac{\alpha_{4}}{\alpha_{2}} L C
\end{aligned}
$$

are the fixed gain parameters in the proposed controller. The method of deriving the control law (16) from originally the equivalent control expression (11) follows the procedure detailed in [29]. Fig. 2 shows a schematic diagram of the derived PWM-based DISM voltage controller for the buck converters.

$$
\left\{\begin{array}{l}
v_{c}=-K_{1} i_{C}+K_{2}\left(V_{\text {ref }}-\beta v_{o}\right)+K_{3} \int\left(V_{\text {ref }}-\beta v_{o}\right) d t+\beta v_{o} \\
\hat{v}_{\text {ramp }}=\beta v_{i}
\end{array}\right.
$$




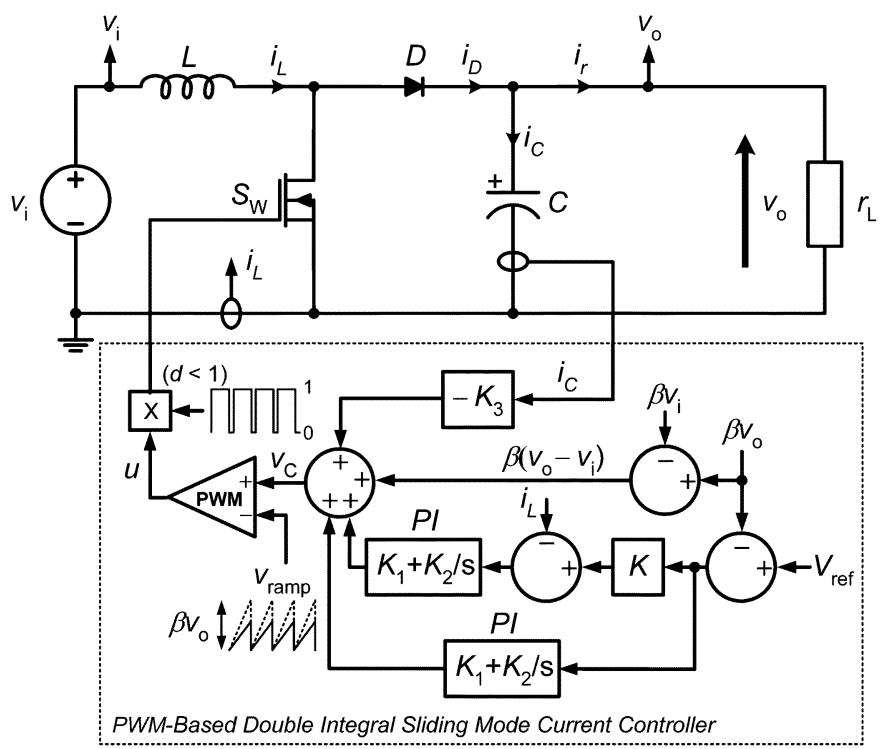

Fig. 3. Proposed pulsewidth modulation based SM current controller for boost converters.

Case 2-Boost Converter: In PWM form, the proposed DISM current controller for the boost converter inherits the expression (18), shown at the bottom of the page, where

$$
\begin{aligned}
K_{1} & =G_{s} \frac{\alpha_{3} L}{\alpha_{1}} ; \quad K_{2}=G_{s} \frac{\alpha_{4} L}{\alpha_{1}} ; \quad \text { and } \\
K_{3} & =G_{s} \frac{\beta L}{C}\left(K+\frac{\alpha_{2}}{\alpha_{1}}\right)
\end{aligned}
$$

are the fixed gain parameters in the proposed controller. A factor of $0<G_{s}<1$ has been introduced to scale down the equation to conform to the chip level voltage standard. Assuming $\beta=G_{s}$, the analog implementation of the derived PWM-based DISM current controller for the boost converters is illustrated in Fig. 3.

Remark: The only physical difference between the PWMbased DISM controllers and the PWM-based ISM controllers [29], [32], are the additional integral state variable's terms, i.e., $K_{3} \int\left(V_{\text {ref }}-\beta v_{o}\right) d t$ and $K_{2} \int\left[K\left(V_{\text {ref }}-\beta v_{o}\right)-i_{L}\right] d t$. Note that in analog implementation, the proportional $(\mathrm{P})$ and integral (I) components can be easily grouped into a single proportional-integral (PI) type computation. Hence, the complexity of the implementation is similar between the PWM-based ISM controllers and the PWM-based DISM controllers.

\section{Existence Condition}

It is necessary to derive the existence condition ${ }^{4}$, which determines the ranges of employable gain parameters $K_{n=1,2,3}$ before the design can be proceeded. To ensure the existence of

\footnotetext{
${ }^{4}$ Satisfaction of the existence condition ensures that the state trajectory at locations near the sliding surface will always be directed towards the sliding sur-
} face.

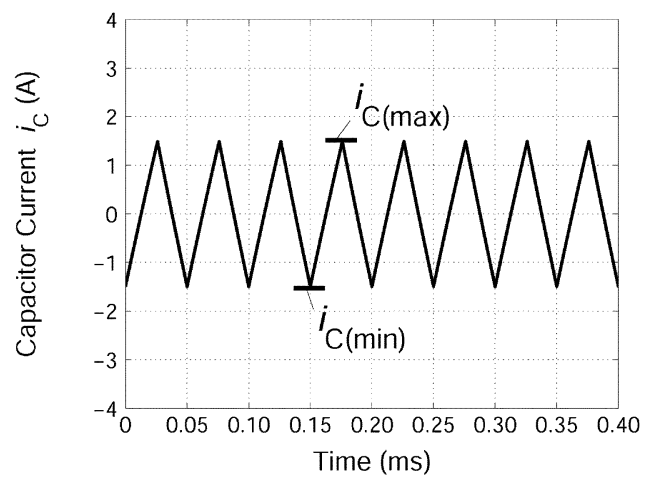

(a)

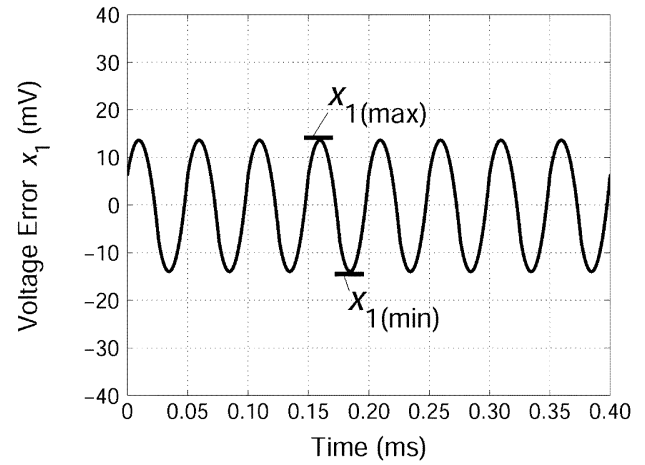

(b)

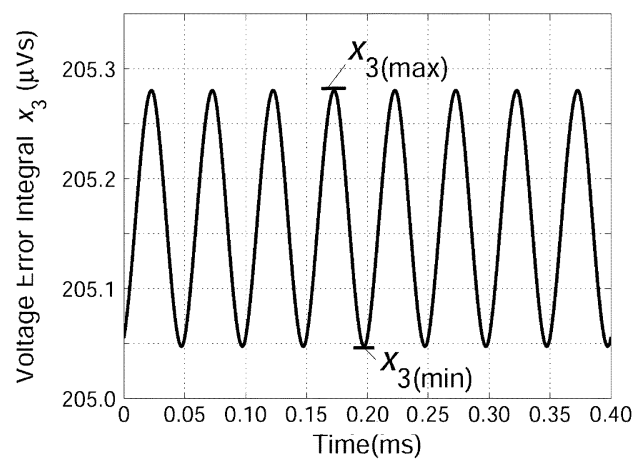

(c)

Fig. 4. Steady-state waveforms of the various state variables of the buck converter at minimum input voltage and full-load condition under ideal open-loop control with negligible output voltage steady-state error. (a) Capacitor current $i_{C}$. (b) Voltage error $x_{1}$, (c) Integral of voltage error $x_{4}$.

SM operation, the local reachability condition $\lim _{S \rightarrow 0} S \cdot \dot{S}<0$ must be satisfied. This can be expressed as

$$
\left\{\begin{array}{l}
\dot{S}_{S \rightarrow 0^{+}}<0 \\
\dot{S}_{S \rightarrow 0^{-}}>0
\end{array} .\right.
$$

Case 1-Buck Converter: For the DISM voltage controlled buck converter, the existence condition for steady-state operations (equilibrium point) [8], [18], [34], can be derived by substituting (8) and its time derivative into (20) with the consid-

$$
\left\{\begin{array}{l}
v_{c}=K_{1}\left(V_{\mathrm{ref}}-\beta v_{o}\right)+K_{2} \int\left(V_{\mathrm{ref}}-\beta v_{o}\right) d t+K_{1}\left[K\left(V_{\mathrm{ref}}-\beta v_{o}\right)-i_{L}\right] \\
\quad+K_{2} \int\left[K\left(V_{\mathrm{ref}}-\beta v_{o}\right)-i_{L}\right] d t-K_{3} i_{C}+G_{s}\left(v_{o}-v_{i}\right) \\
\hat{v}_{\mathrm{ramp}}=G_{s} v_{o}
\end{array}\right.
$$




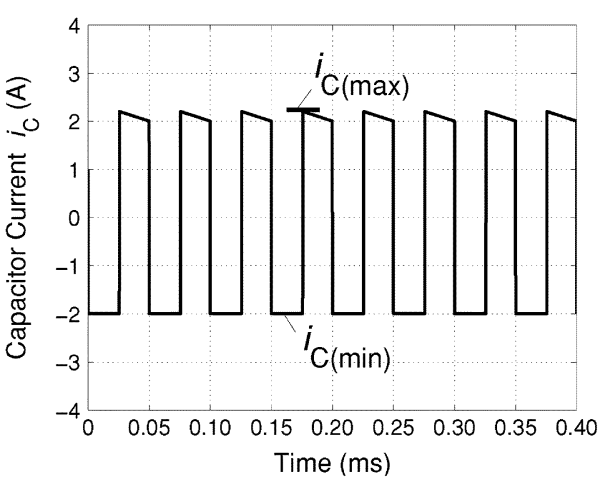

(a)

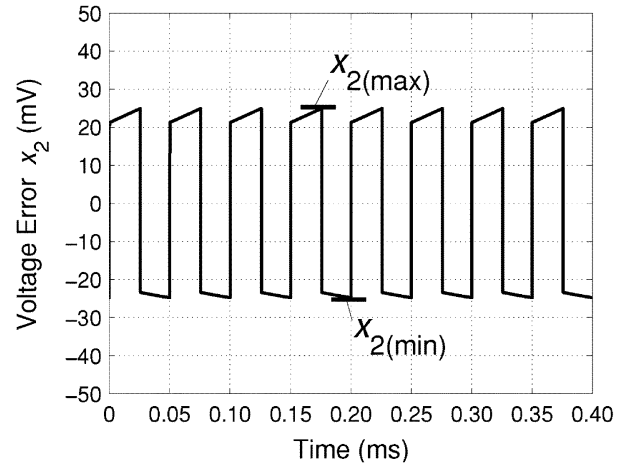

(c)

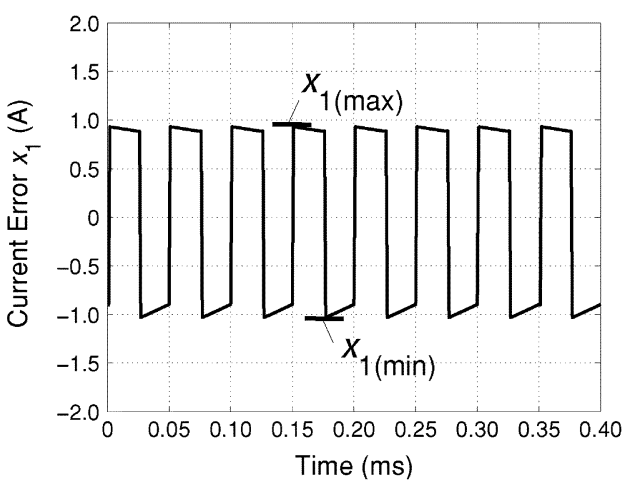

(b)

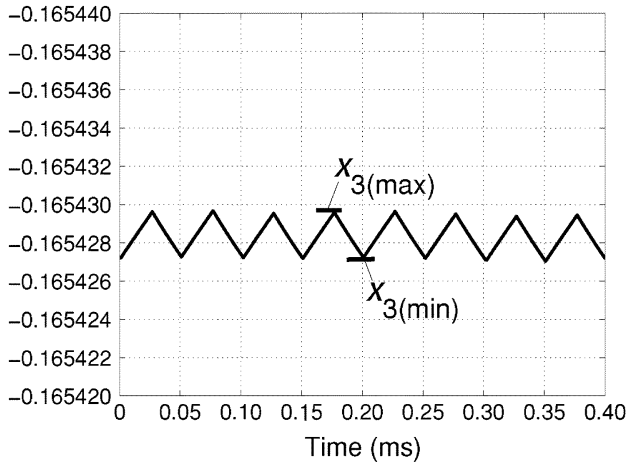

(d)

Fig. 5. Steady-state waveforms of the various state variables of the boost converter at minimum input voltage and full-load condition under ideal open-loop control with negligible output voltage steady-state error: (a) capacitor current $i_{C}$, (b) current error $x_{1}$, (c) voltage error $x_{2}$, and (d) Integral of sum of voltage and current errors $x_{3}$.

eration of the system's dynamics (10) as (21), shown at the bottom of the page, where $v_{\mathrm{i}(\mathrm{min})}$ denotes the minimum input voltage; $v_{\mathrm{o}(\mathrm{SS})}$ denotes the expected steady-state output, i.e., approximately the desired reference voltage $V_{\text {ref }} ; i_{C(\max )}$ and $i_{C(\min )}$ are, respectively, the maximum and minimum capacitor currents at full-load condition; $x_{1(\max )}$ and $x_{1(\min )}$ are respectively the maximum and minimum steady-state voltage errors, which in this case are basically the inverse functions of the output voltage ripples; and $x_{3(\max )}$ and $x_{3(\min )}$ are respectively the maximum and minimum integrals of the steady-state voltage error, which is the time integral of the inverse functions of the output voltage ripples with a negligible dc shift. All these parameters can be calculated from the design specification of the converter. Alternatively, computer simulation of the converter under an ideal open-loop control which gives negligible output voltage steady-state error can be performed to obtained this value. An example of this is given in Fig. 4, which shows the waveforms and magnitudes of the various state variables under minimum input voltage and full-load operating condition. Thus, the compliance of the inequalities in (21) through the substitution of the state variables' parameters assures the existence of the SM operation to occur at least in the small region of the origin for all input and output operating conditions.

Case 2-Boost Converter: For the DISM current controlled boost converter, the existence condition for steady-state operations can be derived by substituting (8) and its time derivative into (20) with the consideration of the system's dynamics (14) as (22), shown at the bottom of the page, where $v_{\mathrm{i}(\max )}$ and $v_{\mathrm{i}(\min )}$ denote the maximum and minimum input voltages respectively; $v_{\mathrm{o}(\mathrm{SS})}$ denotes the expected steady-state output, i.e., approximately the desired reference voltage $V_{\text {ref }}$; and $i_{L(\max )}, i_{L(\min )}, i_{C(\max )}$, and $i_{C(\min )}$ are respectively the maximum and minimum inductor and capacitor currents at full-load condition; $x_{1(\max )}$ and $x_{1(\min )}$ are respectively the maximum and minimum steady-state current errors; $x_{2(\max )}$ and $x_{2(\min )}$ are respectively the maximum and minimum

$$
\left\{\begin{array}{l}
-K_{1} i_{C(\min )}+K_{2} x_{1(\max )}+K_{3} x_{3(\max )}<\beta\left(v_{\mathrm{i}(\min )}-v_{\mathrm{o}(\mathrm{ss})}\right) \\
K_{1} i_{C(\max )}-K_{2} x_{1(\min )}-K_{3} x_{3(\min )}<\beta v_{\mathrm{o}(\mathrm{ss})}
\end{array} .\right.
$$

$$
\left\{\begin{array}{l}
-K_{3} i_{C(\min )}+K_{1}\left(x_{1(\max )}+x_{2(\max )}\right)+K_{2} x_{3(\max )}<\beta v_{\mathrm{i}(\min )} \\
K_{3} i_{C(\max )}-K_{1}\left(x_{1(\min )}+x_{2(\min )}\right)-K_{2} x_{3(\min )}<\beta\left(v_{\mathrm{o}(\mathrm{ss})}-v_{\mathrm{i}(\max )}\right)
\end{array}\right.
$$


steady-state voltage errors, which in this case are basically the inverse functions of the output voltage ripples; and $x_{3(\max )}$ and $x_{3(\min )}$ are respectively the maximum and minimum integrals of the combination of steady-state voltage and current errors. Fig. 5 illustrates the physical representations of these parameters. Likewise, design of control parameters must satisfy the inequalities in (22).

Remark: It is worth mentioning that the abidance of the existence condition which takes into consideration the amount of ac perturbation of the state variables, which is a function of time, indirectly counterchecks the minimum allowable switching frequency for a particular control parameter design, i.e., controller bandwidth. This is similar to the conventional controller design approach in which, as a rule of thumb, the crossover frequency of the controller must be kept at least below one quarter of the switching frequency in the case of a buck converter.

\section{Stability Condition}

As in any SM controlled systems, the stability ${ }^{5}$ of the converter under the DISM controller can be achieved by making the eigenvalues of the Jacobian matrix of the system to have negative real parts.

Case 1-Buck Converter: In the DISM voltage controlled buck converter, where the SM equation is the linear motion equation of the converter in SM operation, the stability condition can easily be obtained analytically. This is possible by substituting $S=0$ into (8), i.e.

$$
\alpha_{1} x_{1}+\alpha_{2} x_{2}+\alpha_{3} x_{3}+\alpha_{4} x_{4}=0
$$

to first obtain the motion equation. Since the state variables $x_{n=1,2,3,4}$ are in phase canonical form, (23) can be rewritten in Laplace form as

$$
\begin{aligned}
& \alpha_{1} X(s)+\alpha_{2} s X(s)+\alpha_{3} \frac{X(s)}{s}+\alpha_{4} \frac{X(s)}{s^{2}}=0 \\
\Rightarrow & s^{3}+\frac{\alpha_{1}}{\alpha_{2}} s^{2}+\frac{\alpha_{3}}{\alpha_{2}} s+\frac{\alpha_{4}}{\alpha_{2}}=0 .
\end{aligned}
$$

Finally, applying the Routh's stability criterion to this third order linear polynomial, the conditions for stability are that all the coefficients must be positive, i.e., $0<\alpha_{n=1,2,3,4}$, and that $\alpha_{1} \alpha_{3}>\alpha_{2} \alpha_{4}$ to ensure that all roots have negative real parts. On the other hand, the stability condition can be automatically satisfied by designing the sliding coefficients for a desired dynamic response [29], [34].

Case 2-Boost Converter: For the DISM current controlled boost converter, the motion equation is nonlinear. A different approach based on the equivalent control method is adopted to

\footnotetext{
${ }^{5}$ Satisfaction of the stability condition ensures that the state trajectory of the system under SM operation will always reach a stable equilibrium point.
}

derive the stability condition [18], [28]. This is to first derive the ideal sliding dynamics of the system, and then doing an stability analysis on its equilibrium point.

1) Ideal Sliding Dynamics: The replacement of $\bar{u}$ by $\bar{u}_{\mathrm{eq}}$ (so-called equivalent control method) into the original boost converter's description under CCM operation converts the discontinuous system into an ideal SM continuous system:

$$
\left\{\begin{array}{l}
\frac{d i_{L}}{d t}=\frac{v_{i}}{L}-\frac{v_{o}}{L} \bar{u}_{\mathrm{eq}} \\
\frac{d v_{o}}{d t}=\frac{i_{L}}{C} \bar{u}_{\mathrm{eq}}-\frac{v_{o}}{r_{L} C}
\end{array} .\right.
$$

Then, the substitution of the equivalent control signal into (25) gives (26), shown at the bottom of the page, which represents the ideal sliding dynamics of the SM current controlled boost converter.

2) Equilibrium Point: Assume that there exists a stable equilibrium point on the sliding surface on which the ideal sliding dynamics eventually settled. At this point of equilibrium (steady state), there will not be any change in the system's dynamics if there is no input or loading disturbance, i.e., $\left(d i_{L} / d t\right)=$ $\left(d v_{o} / d t\right)=0$. Then, the state equations in (26) can be equated to give

$$
I_{L}=\frac{V_{o}^{2}}{V_{i} R_{L}}
$$

where $I_{L}, V_{o}, V_{i}$, and $R_{L}$ represents the inductor current, output voltage, input voltage, and load resistance at steady-state equilibrium, respectively.

3) Linearization of Ideal Sliding Dynamics: Next, the linearization of the ideal sliding dynamics around the equilibrium point transforms (26) into

$$
\left\{\begin{array}{l}
\frac{d \tilde{i}_{L}}{d t}=a_{11} \tilde{i}_{L}+a_{12} \tilde{v}_{o}+a_{13} \int \tilde{i}_{L} d t+a_{14} \int \tilde{v}_{o} d t \\
\frac{d \tilde{v}_{o}}{d t}=a_{21} \tilde{i}_{L}+a_{22} \tilde{v}_{o}+a_{23} \int \tilde{i}_{L} d t+a_{24} \int \tilde{v}_{o} d t \\
\frac{d\left[\int \tilde{i}_{L} d t\right]}{d t}=a_{31} \tilde{i}_{L}+a_{32} \tilde{v}_{o}+a_{33} \int \tilde{i}_{L} d t+a_{34} \int \tilde{v}_{o} d t \\
\frac{d\left[\int \tilde{v}_{o} d t\right]}{d t}=a_{41} \tilde{i}_{L}+a_{42} \tilde{v}_{o}+a_{43} \int \tilde{i}_{L} d t+a_{44} \int \tilde{v}_{o} d t
\end{array}\right.
$$

where you have (29), shown at the bottom of the next page. The derivation is performed with the adoption of the following static equilibrium conditions, $V_{i}=v_{i}, R_{L}=r_{L}, V_{\text {ref }}-\beta V_{o}=0$, and $I_{\text {ref }}=I_{L}=K\left(V_{\text {ref }}-\beta V_{o}\right)$, and the assumptions $K \gg$ $1, I_{L} \gg \tilde{i}_{L}$ and $V_{o} \gg \tilde{v}_{o}$. Therefore, the characteristic equation of the linearized system is given by

$$
\begin{aligned}
\left|\begin{array}{cccc}
s-a_{11} & -a_{12} & -a_{13} & -a_{14} \\
-a_{21} & s-a_{22} & -a_{23} & -a_{24} \\
-1 & 0 & s & 0 \\
0 & -1 & 0 & s
\end{array}\right| \\
\quad=s^{4}+p_{1} s^{3}+p_{2} s^{2}+p_{3} s+p_{4}=0
\end{aligned}
$$

$$
\left\{\begin{aligned}
\frac{d i_{L}}{d t} & =\frac{v_{i}}{L}-\frac{v_{o}}{L} \frac{K_{1} \frac{v_{o}}{r_{L}}-v_{i}+K_{2}\left[V_{\mathrm{ref}}-\beta v_{o}\right]+K_{2}\left[i_{\mathrm{ref}}-i_{L}\right]+K_{3} \int\left[V_{\mathrm{ref}}-\beta v_{o}\right] d t+K_{3} \int\left[i_{\mathrm{ref}}-i_{L}\right] d t}{K_{1} i_{L}-v_{o}} \\
\frac{d v_{o}}{d t} & =\frac{i_{L}}{C} \frac{K_{1} \frac{v_{o}}{r_{L}}-v_{i}+K_{2}\left[V_{\mathrm{ref}}-\beta v_{o}\right]+K_{2}\left(i_{\mathrm{ref}}-i_{L}\right)+K_{3} \int\left[V_{\mathrm{ref}}-\beta v_{o}\right] d t+K_{3} \int\left[i_{\mathrm{ref}}-i_{L}\right] d t}{K_{1} i_{L}-v_{o}}-\frac{v_{o}}{r_{L} C}
\end{aligned}\right.
$$


where

$$
\left\{\begin{array}{l}
p_{1}=-a_{11}-a_{22} \\
p_{2}=a_{11} a_{22}-a_{12} a_{21}-a_{13}-a_{24} \\
p_{3}=a_{11} a_{24}+a_{13} a_{22}-a_{12} a_{23}-a_{14} a_{21} a_{14} \\
p_{4}=a_{13} a_{24}-a_{14} a_{23}
\end{array} .\right.
$$

The application of the Routh criterium to the characteristic (30) shows that the system will be stable if the following conditions are satisfied

$$
\left\{\begin{array}{l}
p_{1}>0 \\
p_{2}>\frac{p_{3}}{p_{1}} \\
p_{3}>\frac{p_{1} p_{4}}{p_{2}-\frac{p_{3}}{p_{1}}} \\
p_{4}>0
\end{array}\right.
$$

Hence, by numerically solving (29) and substituting its solutions into (32), the stability of the system can be determined. This, along with the existence condition (22), form the basis for the selection and design of the control gains of the proposed DISM controllers in terms of the converter's specification. The compliance of the stability condition assures that there exists an equilibrium point on the sliding surface, and the compliance of the existence condition assures that the state trajectory tracks the surface to this point of equilibrium.

\section{RESULTS AND DisCUSSIONS}

The idea of using the DISM controllers on the power converters is tested on various topologies. In this section, computer simulation results of the PWM-based DISM buck converter and experimental results of the PWM-based DISM boost converter are provided for validation and discussion.

\section{A. Simulation Result of PWM-Based DISM Buck Converter}

The performance of the proposed PWM-based DISM voltage controlled buck converter shown in Fig. 2 is verified and compared to the PWM-based ISM voltage controlled buck converter [29] through computer simulations ${ }^{6}$. The specification of the converter is given in Table I.

Here, the PWM-based ISM controller is designed to give a critically-damped response with a bandwidth of $f_{\mathrm{BW}}=2.5 \mathrm{kHz}$. Using equations derived in [29], the sliding coefficients are $\left(\alpha_{1} / \alpha_{2}\right)=4 \pi f_{\mathrm{BW}}=31415.93$ and $\left(\alpha_{3} / \alpha_{2}\right)=4 \pi^{2} f_{\mathrm{BW}}{ }^{2}=246740110$. The reference voltage is set as $V_{\text {ref }}=2.5 \mathrm{~V}$, which gives $\beta=\left(V_{\text {ref }} / V_{\text {od }}\right)=0.208$. Designing for the maximum load resistance, the control parameters are determined as $K_{1}=\beta L\left(\left(\alpha_{1} / \alpha_{2}\right)-\left(1 / r_{L} C\right)\right)=$

\footnotetext{
${ }^{6}$ The simulations are performed using Matlab/Simulink. The step size taken for all simulations is $10 \mathrm{~ns}$. Interested readers may email the corresponding author for a set of the test programs.
}

TABLE I

SPECIFICATION OF BUCK CONVERTER

\begin{tabular}{|lcc|}
\hline Description & Parameter & Nominal Value \\
\hline Input voltage & $v_{\mathrm{i}}$ & $24 \mathrm{~V}$ \\
Capacitance & $C$ & $150 \mu \mathrm{F}$ \\
Capacitor ESR & $r_{C}$ & $21 \mathrm{~m} \Omega$ \\
Inductance & $L$ & $100 \mu \mathrm{H}$ \\
Inductor resistance & $r_{L}$ & $0.12 \Omega$ \\
Switching frequency & $f_{\mathrm{S}}$ & $20 \mathrm{kHz}$ \\
Minimum load resistance & $r_{\mathrm{L}(\min )}$ & $0.75 \Omega$ \\
Maximum load resistance & $r_{\mathrm{L}(\max )}$ & $3 \Omega$ \\
Desired output voltage & $V_{\mathrm{od}}$ & $12 \mathrm{~V}$ \\
\hline
\end{tabular}

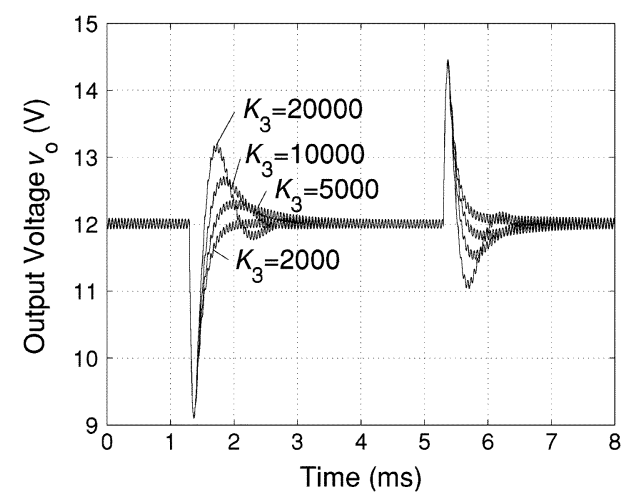

Fig. 6. Output voltage waveforms of the PWM-based DISM voltage controlled buck converter operating at step load changes alternating between $3 \Omega$ and $0.75 \Omega$ for various values of $K_{3}$.

0.608 and $K_{2}=\left(\alpha_{3} / \alpha_{2}\right) L C=3.701$. Therefore, the implemented control signal equation is

$$
v_{\mathrm{c}}=-0.608 i_{C}+0.208 v_{o}+3.701\left(V_{\mathrm{ref}}-\beta v_{o}\right) .
$$

To compare the effect of the pole addition to the controller, the same parameters of $K_{1}$ and $K_{2}$ used in the ISM controller are employed in the case of the DISM controller. Hence, the equation of the control signal for the PWM-based DISM controller is

$$
\begin{array}{rl}
v_{c}=-0.608 i_{C}+0.208 v_{o}+3 & .701\left(V_{\mathrm{ref}}-\beta v_{o}\right) \\
& +K_{3} \int\left(V_{\mathrm{ref}}-\beta v_{o}\right) d t .
\end{array}
$$

Fig. 6 shows the output voltage waveforms of the PWMbased DISM voltage controlled buck converter for various values of $K_{3}$. It is worth mentioning that the steady-state

$$
\left\{\begin{array}{l}
a_{11}=\frac{K_{2} V_{i} R_{L}}{K_{1} L V_{o}-L V_{i} R_{L}} ; \quad a_{12}=-\frac{K_{1} 2 V_{i}-\frac{V_{i}^{2} R_{L}}{V_{o}}-K_{2} K \beta \frac{V_{i}}{R_{L}}}{K_{1} L V_{o}-L V_{i} R_{L}} ; \quad a_{13}=\frac{K_{3} V_{i} R_{L}}{K_{1} L V_{o}-L V_{i} R_{L}} ; \quad a_{14}=\frac{K_{3} K \beta \frac{V_{i}}{R_{L}}}{K_{1} L V_{o}-L V_{i} R_{L}} ; \\
a_{21}=\frac{K_{1} V_{i}-\frac{V_{i}^{2} R_{L}}{V_{o}}-K_{2} V_{o}}{K_{1} V_{o} C-C V_{i} R_{L}} ; \quad a_{22}=\frac{V_{i}-K_{2} K \beta V_{o}}{K_{1} V_{o} C-C V_{i} R_{L}} ; \quad a_{23}=\frac{K_{3} V_{o}}{K_{1} V_{o} C-C V_{i} R_{L}} ; \quad a_{24}=\frac{K_{3} K \beta V_{o}}{K_{1} V_{o} C-C V_{i} R_{L}} ; \\
a_{31}=1 ; \quad a_{32}=0 ; \quad a_{33}=0 ; \quad a_{34}=0 ; \\
a_{41}=0 ; \quad a_{42}=1 ; \quad a_{43}=0 ; \quad a_{34}=0 .
\end{array}\right.
$$




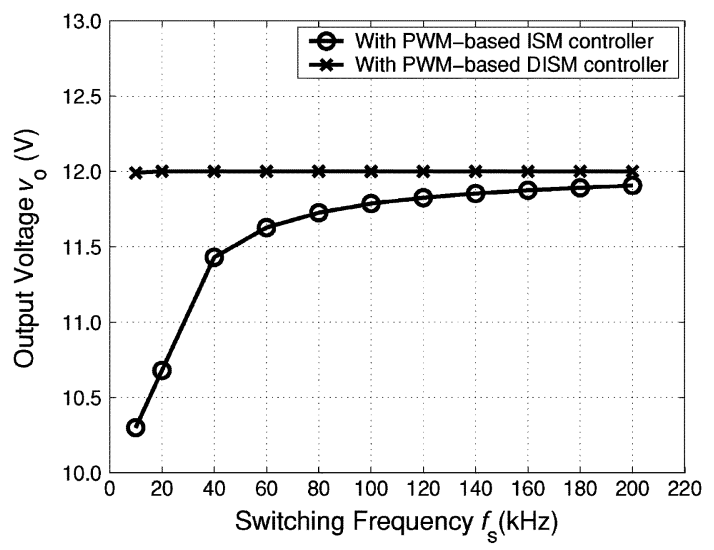

(a)

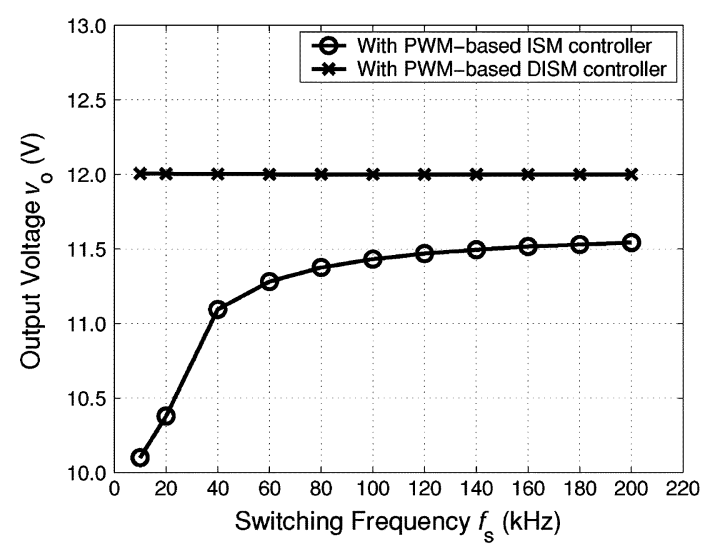

(b)

Fig. 7. Plot of steady-state output voltage $v_{o}$ against switching frequency $f_{s}$ of the buck converter operating under the PWM-based ISM and DISM controllers at (a) maximum and (b) minimum load resistances. (a) At maximum load resistance $r_{L}=3 \Omega$, (b) At minimum load resistance $r_{L}=0.75 \Omega$.

voltage error is near zero for all cases of $K_{3}$. The choice of $K_{3}$ is therefore based on the required damping response.

Hereon, the simulations of the DISM controller are performed with the parameter $K_{3}=2000$, which is chosen for its critically damned response. Fig. 7(a) and (b) show the plots of the steady-state output voltage against the switching frequency of the buck converter under the PWM-based ISM and DISM controllers for respectively the maximum and minimum load resistances. As expected, the result shows that the addition of the double-integral term of the state variables does nullify the steady-state error of the converter for all switching frequencies.

Fig. 8(a)-(c) show the output voltage waveforms of the buck converter operating at $20 \mathrm{kHz}$ and step load changes alternating between $3 \Omega$ and $0.75 \Omega$, under the PWM-based ISM controller at standard $V_{\text {ref }}$ level, the PWM-based ISM controller with uplifted $V_{\text {ref }}$ level, and the PWM-based DISM controller at standard $V_{\text {ref level, respectively. Fig. 8(a) shows the typical output }}$ voltage waveform expected in a low-switching-frequency ISM voltage controlled buck converter. The output voltage is poorly regulated with a high steady-state error, i.e., $v_{o}=10.4 \mathrm{~V}$ at minimum load resistance and $v_{o}=10.7 \mathrm{~V}$ at maximum load resistance. As mentioned, in practice, it is possible to raise the reference setpoint to obtain the desired output voltage. This is demonstrated in Fig. 8(b), where $V_{\text {ref }}$ is raised from the original value of $2.5 \mathrm{~V}$ to $2.78 \mathrm{~V}$. Here, it can be seen that at maximum load resistance, the output voltage is regulated at $12 \mathrm{~V}$. However, at minimum load resistance, the output voltage is only $11.7 \mathrm{~V}$. This verifies what has been earlier discussed, that is, this method of reference-voltage-shifting correction does not alleviate the steady-state error of the converter. Finally, it is illustrated in Fig. 8(b) that by converting the ISM controller into a DISM controller and with a proper choice of parameter $K_{3}$, it is possible to derive a PWM-based (indirect) type of SM controller that achieves near perfect regulation even at a low switching frequency, and that has similarly good dynamical features as the ISM controller.

\section{B. Experimental Result of PWM-Based DISM Boost Converter}

The performance of the proposed PWM-based DISM current controlled boost converter shown in Fig. 3 is experimentally verified and compared to the PWM-based ISM current controlled boost converter [32]. The specification of the converter is given in Table II.

Here, the PWM-based ISM controller is optimally tuned using the approach proposed in [32] to give the fastest critically-damped response. The reference voltage is fixed at $V_{\text {ref }}=8 \mathrm{~V}$, which makes $\beta=G_{s}=0.167$. The implemented control signal equation is

$$
\begin{array}{r}
v_{\mathrm{c}}=-i_{C}+4.167\left(V_{\mathrm{ref}}-0.167 v_{o}\right) \\
-0.77 i_{L}+0.167\left(v_{o}-v_{i}\right) .
\end{array}
$$

Next, the PWM-based DISM controller is also tuned to give the fastest critically-damped response. Here, the integral term $K_{2} \int\left[K\left(V_{\text {ref }}-\beta v_{o}\right)-i_{L}\right] d t$ of the original (18) is ignored to simplify circuit implementation. This is possible under the knowledge that the inductor current error is negligible because of the high current-error gain value of $K^{7}$. The final form of the control signal equation adopted in the experiment is

$$
\begin{aligned}
v_{\mathrm{c}}= & -i_{C}+1.58\left(V_{\mathrm{ref}}-0.167 v_{o}\right) \\
& +K_{2} \int\left(V_{\mathrm{ref}}-\beta v_{o}\right) d t-0.77 i_{L}+0.167\left(v_{o}-v_{i}\right) .
\end{aligned}
$$

A comparison between (35) and (36) shows that with the additional integral term of $K_{2} \int\left(V_{\text {ref }}-\beta v_{o}\right) d t$, the gain value of $V_{\text {ref }}-0.167 v_{o}$ has been lowered to 1.58 in the DISM controller. The reduction in the proportional gain is to tackle the instability due to the introduction of the integral pole term.

Fig. 9 shows the output voltage waveforms of the PWMbased DISM voltage controlled boost converter for various gains of the integral term, i.e., $K_{2}=720,1220$, and 1930. Notably, the steady-state dc voltage error is alleviated for all three cases. Also, the variations in the dynamic behavior due to the respective $K_{2}$ value can be observed from the figure. Hereon, the experiments of the DISM controller are performed with the parameter $K_{2}=1220$, which is chosen for its critically damped response.

Fig. 10(a) and (b) show the plots of the steady-state output voltage against the switching frequency of the boost converter

\footnotetext{
${ }^{7}$ In the case where the gain value is small or that a large inductor current error is present, the integral term is required.
} 


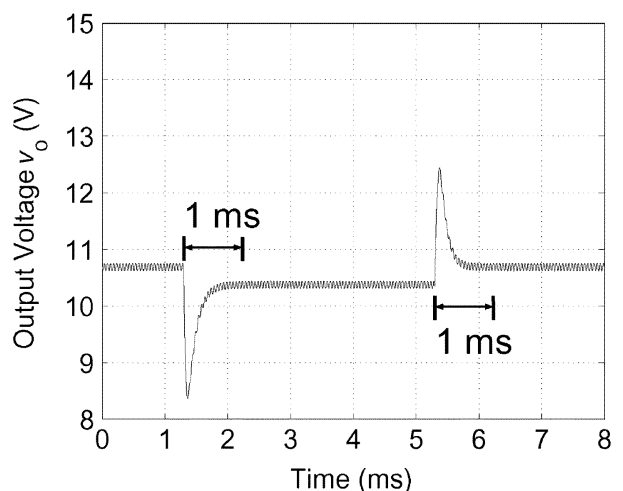

(a)

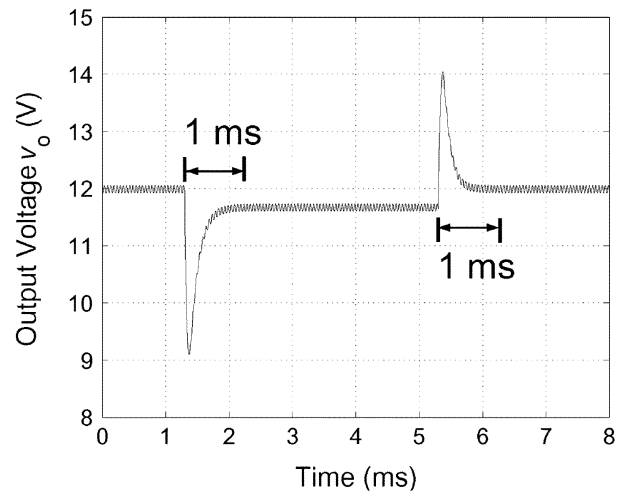

(b)

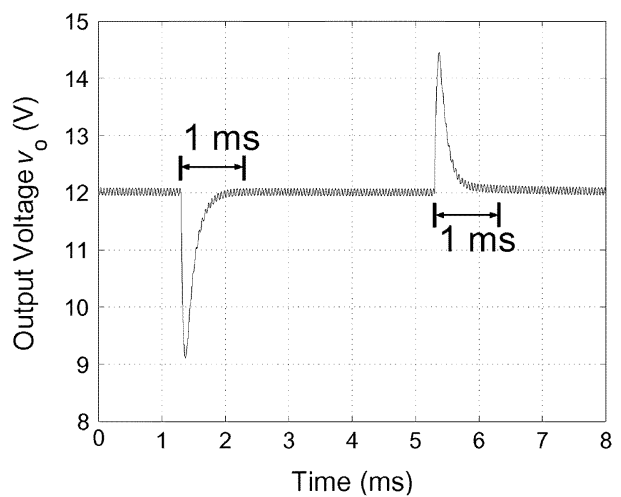

(c)

Fig. 8. Output voltage waveforms of a $24 \mathrm{~V}$ input, $12 \mathrm{~V}$ output buck converter operating at step load changes alternating between $3 \Omega$ and $0.75 \Omega$ under (a) a PWM-based ISM controller at standard $V_{\text {ref level; (b) a PWM-based ISM }}$ controller with uplifted $V_{\text {ref }}$ level; and (c) a PWM-based DISM controller at standard $V_{\text {ref }}$ level. (a) ISM controller with $V_{\text {ref }}=2.5 \mathrm{~V}$, (b) ISM controller with $V_{\text {ref }}=2.78 \mathrm{~V}$, (c) DISM controller with $V_{\text {ref }}=2.5 \mathrm{~V}$.

under the PWM-based ISM and DISM controllers for respectively the minimum and maximum output currents. According to the experimental readings, the addition of the double-integral term of the state variables into the PWM ISM controller reduces the steady-state regulation error (between minimum and maximum output currents) from $<1 \%$ to $<0.05 \%$ for all values of switching frequency. Hence, the strength of the proposed solution in alleviating the steady-state error of PWM ISM controller is illustrated.

Fig. 11(a) and (b) show the output voltage waveforms of the boost converter operating at $200 \mathrm{kHz}$ and step load changes alternating between $0.5 \mathrm{~A}$ and $2 \mathrm{~A}$, under the PWM-based ISM
TABLE II

SPECIFICATION OF BOOST CONVERTER

\begin{tabular}{|lcc|}
\hline Description & Parameter & Nominal Value \\
\hline Input voltage & $v_{\mathrm{i}}$ & $24 \mathrm{~V}$ \\
Capacitance & $C$ & $220 \mu \mathrm{F}$ \\
Capacitor ESR & $r_{C}$ & $25 \mathrm{~m} \Omega$ \\
Inductance & $L$ & $300 \mu \mathrm{H}$ \\
Inductor resistance & $r_{L}$ & $0.14 \Omega$ \\
Switching frequency & $f_{\mathrm{S}}$ & $200 \mathrm{kHz}$ \\
Minimum output current & $i_{r(\min )}$ & $0.5 \mathrm{~A}$ \\
Maximum output current & $i_{r(\max )}$ & $2 \mathrm{~A}$ \\
Desired output voltage & $V_{\mathrm{od}}$ & $48 \mathrm{~V}$ \\
\hline
\end{tabular}

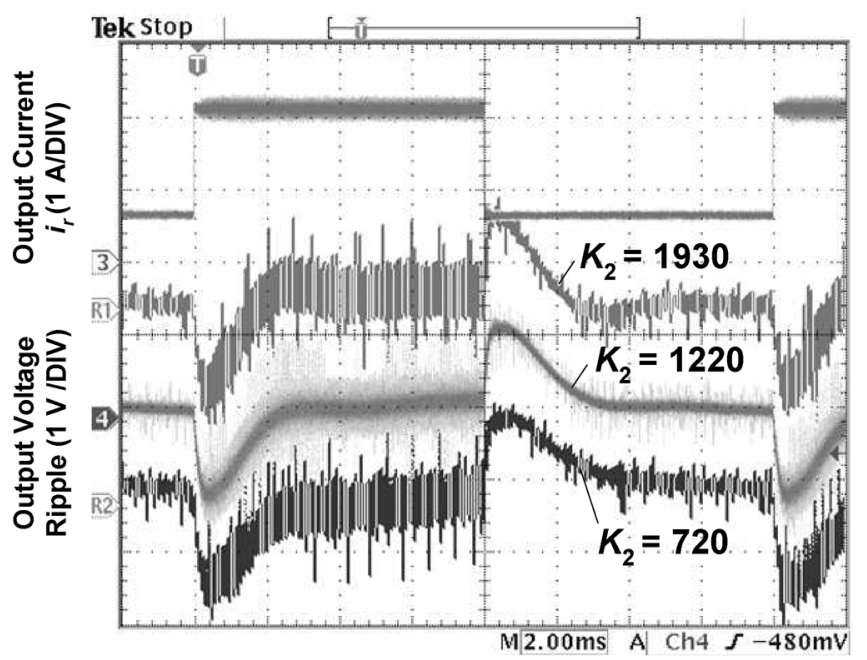

Fig. 9. Output voltage waveforms of the PWM-based DISM voltage controlled boost converter operating at step load changes alternating between 0.5 and $2 \mathrm{~A}$ for various values of integral capacitors.

controller and the PWM-based DISM controller, respectively. As seen from the figures, both controllers displayed excellent large-signal property (a major feature of the SM control) of having a consistent response for both step up and down load changes. However, with the PWM-based ISM controller, the converter contains a significant level of steady-state error of around $400 \mathrm{mV}$ [see Fig. 11(a)]. Such error is not present with the PWM-based DISM controller [see Fig. 11(b)]. Yet, it can be seen that with the PWM-based ISM controller, a faster dynamical response can be achieved. This is due to the higher value of the voltage-error control gain in the PWM-based ISM controller (gain value of 4.167) than the PWM-based DISM controller (gain value of 1.58) [refer to (35) and (36)]. Hence, it is important to remark that even though the steady-state error of the PWM-based ISM controller can be alleviated to achieve near perfect regulation by converting it into the DISM controller, it may come at the expense of a lower allowable proportional gain value, which gives a slower dynamical response. Otherwise, in systems which the same gain value can be employed for both the PWM-based ISM and DISM controllers, similarly good dynamical features can be obtained with both controllers as illustrated in the example with the buck converter. 


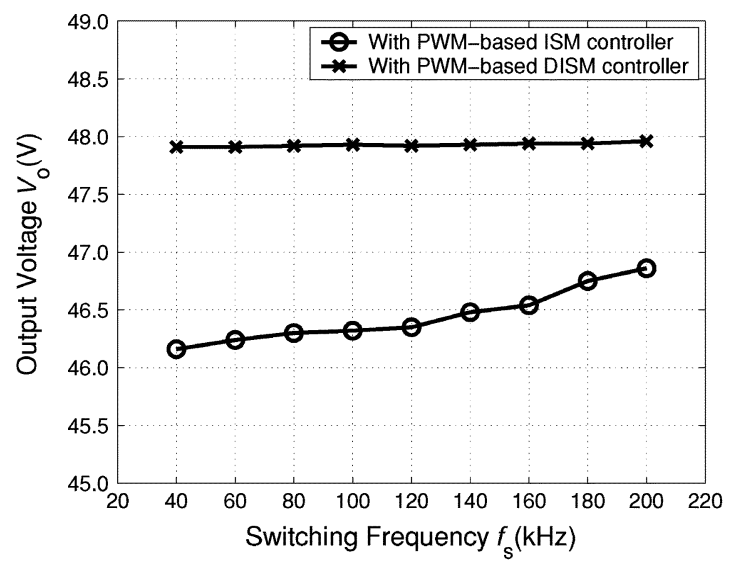

(a)

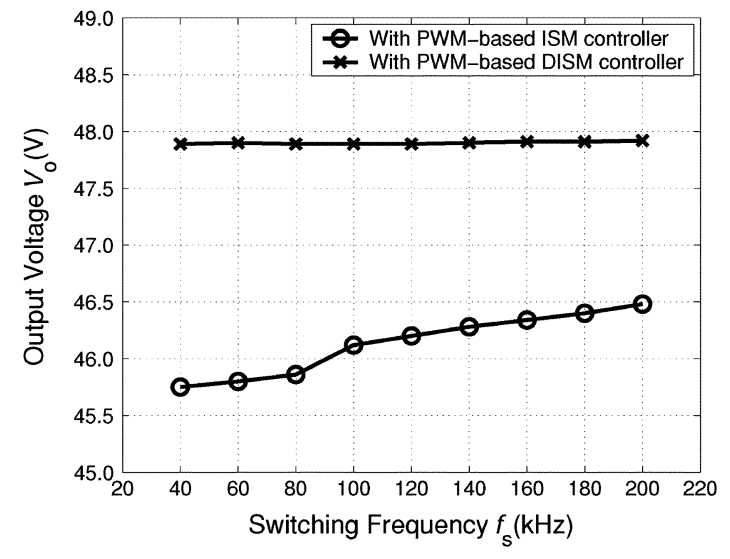

(b)

Fig. 10. Plot of steady-state output voltage $v_{o}$ against switching frequency $f_{s}$ of the boost converter operating under the PWM-based ISM and DISM controllers at (a) minimum and (b) maximum output currents. (a) At minimum output current $i_{r}=0.5 \mathrm{~A}$. (b) At maximum output current $i_{r}=2.0 \mathrm{~A}$.

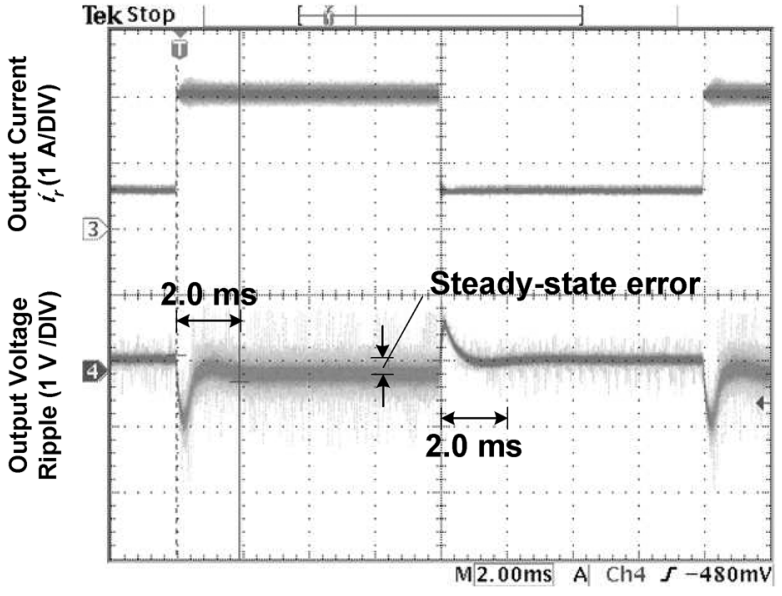

(a)

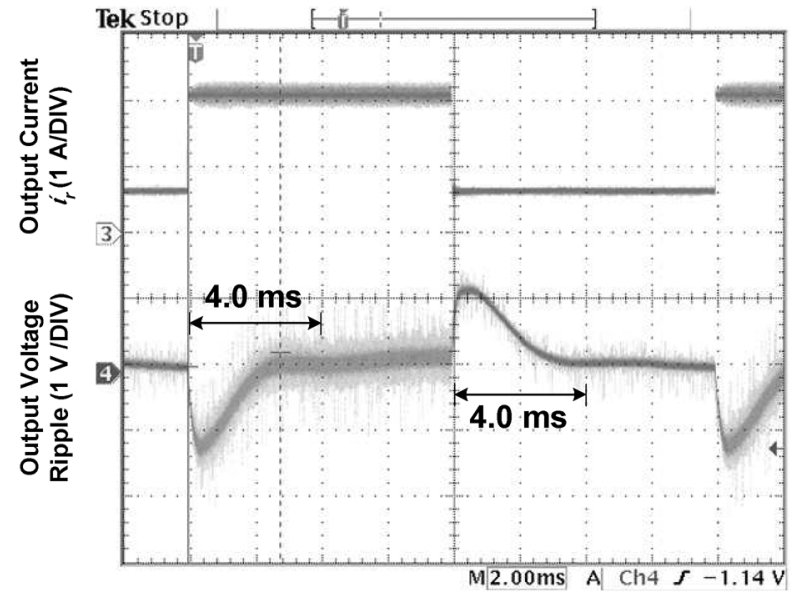

(b)

Fig. 11. Output voltage waveforms of a $24 \mathrm{~V}$ input, $48 \mathrm{~V}$ output boost converter operating at step load changes alternating between $0.5 \mathrm{~A}$ and $2 \mathrm{~A}$ under (a) the PWM-based ISM controller; and (b) the PWM-based DISM controller. (a) ISM controller and (b) DISM controller.

\section{CONCLUSION}

In this paper, the failure of the integral control scheme in the indirect form of ISM controllers in alleviating the steady-state regulation error of power converters has been examined. It is found that the problem of the method of steady-state error correction in these controllers lies in the use of an indirect method of computing the integral of the steady-state error. Notably, the magnitude of the regulation error increases as the switching frequency reduces, and it becomes prominent at the low frequency range. In view of this, it is proposed that a double-integral term of the controlled variables can be added for constructing the sliding surface of indirect SM controllers. The inclusion of this additional term is to correct the error of the indirect integral computation. By doing so, the regulation error of the converter is indirectly alleviated. Tests including computer simulation and experiment have been carried out on the PWM form of indirect SM controllers to verify the idea. It has been shown that the proposed DISM controller is capable of achieving a near perfect regulation even at a low switching frequency.

\section{ACKNOWLEDGMENT}

The authors would like to acknowledge the contribution of C. $\mathrm{K}$. Wu for his assistance in conducting the experiment.

\section{REFERENCES}

[1] V. Utkin, J. Guldner, and J. X. Shi, Sliding Mode Control in Electromechanical Systems. London, U.K.: Taylor and Francis, 1999.

[2] M. N. Marwali, J. W. Jung, and A. Keyhani, "Control of distributed generation systems-Part II: load sharing control," IEEE Trans. Power Electron., vol. 19, no. 6, pp. 1551-1561, Nov. 2004.

[3] M. Gokasan, S. Bogosyan, and D. J. Goering, "Sliding mode based powertrain control for efficiency improvement in series hybrid-electric vehicles," IEEE Trans. Power Electron., vol. 21, no. 3, pp. 779-790, May 2006.

[4] R.-J. Wai and C.-H. Tu, "Design of total sliding-mode-based genetic algorithm control for hybrid resonant-driven linear piezoelectric ceramic motor," IEEE Trans. Power Electron., vol. 22, no. 2, pp. 563-575, Mar. 2007.

[5] J. W. Jung and A. Keyhani, "Control of a fuel cell based Z-source converter," IEEE Trans. Energy Conv., vol. 22, no. 2, pp. 467-476, Jun. 2007.

[6] F.-J. Lin, C.-K. Chang, and P.-K. Huang, "FPGA-based adaptive backstepping sliding-mode control for linear induction motor drive," IEEE Trans. Power Electron., vol. 22, no. 4, pp. 1222-1231, Jul. 2007.

[7] B. J. Cardoso, A. F. Moreira, B. R. Menezes, and P. C. Cortizo, "Analysis of switching frequency reduction methods applied to sliding mode controlled DC-DC converters," in Proc. IEEE Appl. Power Electron. Conf. Expo (APEC), Feb. 1992, pp. 403-410.

[8] E. Fossas, L. Martínez, and J. Ordinas, "Sliding mode control reduces audiosusceptibility and load perturbation in the Cuk converter," IEEE Trans. Circuits Syst. I, vol. 39, no. 10, pp. 847-849, Oct. 1992.

[9] P. Mattavelli, L. Rossetto, G. Spiazzi, and P. Tenti, "General-purpose sliding-mode controller for dc-dc converter applications," in Proc. IEEE Power Electron. Spec. Conf. (PESC), Jun. 1993, pp. 609-615. 
[10] L. Rossetto, G. Spiazzi, P. Tenti, B. Fabiano, and C. Licitra, "Fastresponse high-quality rectifier with sliding mode control," IEEE Trans. Power Electron., vol. 9, no. 2, pp. 146-152, Mar. 1994.

[11] L. Malesani, L. Rossetto, G. Spiazzi, and P. Tenti, "Performance optimization of Ćuk converters by sliding-mode control," IEEE Trans. Power Electron., vol. 10, no. 3, pp. 302-309, May 1995.

[12] V. M. Nguyen and C. Q. Lee, "Tracking control of buck converter using sliding-mode with adaptive hysteresis," in Proc. IEEE Power Electron. Spec. Conf. (PESC), Jun. 1995, vol. 2, pp. 1086-1093.

[13] D. Casini, M. Marchesoni, and L. Puglisi, "Sliding mode multilevel control for improved performances in power conditioning systems," IEEE Trans. Power Electron., vol. 10, no. 4, pp. 453-463, Jul. 1995.

[14] V. M. Nguyen and C. Q. Lee, "Indirect implementations of slidingmode control law in buck-type converters," in Proc. IEEE Appl. Power Electron. Conf. Expo (APEC), Mar. 1996, vol. 1, pp. 111-115.

[15] S. L. Jung and Y. Y. Tzou, "Discrete sliding-mode control of a PWM inverter for sinusoidal output waveform synthesis with optimal sliding curve," IEEE Trans. Power Electron., vol. 11, no. 4, pp. 567-577, Jul. 1996.

[16] P. Mattavelli, L. Rossetto, and G. Spiazzi, "Small-signal analysis of DC-DC converters with sliding mode control," IEEE Trans. Power Electron., vol. 12, no. 1, pp. 96-102, Jan. 1997.

[17] J. Mahdavi, A. Emadi, and H. A. Toliyat, "Application of state space averaging method to sliding mode control of PWM DC/DC converters," in Proc. IEEE Conf. Ind. Appl. (IAS), Oct. 1997, vol. 2, pp. 820-827.

[18] L. Martinez-Salamero, J. Calvente, R. Giral, A. Poveda, and E. Fossas, "Analysis of a bidirectional coupled-inductor Ćuk converter operating in sliding mode," IEEE Trans. Circuits Syst. I, vol. 45, no. 4, pp. 355-363, Apr. 1998.

[19] G. Escobar, R. Ortega, H. Sira-Ramirez, J. P. Vilain, and I. Zein, “An experimental comparison of several nonlinear controllers for power converters," IEEE Contr. Syst. Mag., vol. 19, no. 1, pp. 66-82, Feb. 1999.

[20] J. Mahdavi, M. R. Nasiri, and A. Agah, "Application of neural networks and state space averaging to a DC/DC PWM converter in sliding mode operation," in Proc. IEEE Conf. Ind. Electron., Contr. Instrum. (IECON), 2000, vol. 1, pp. 172-177.

[21] M. Castilla, L. C. de Vicuna, M. Lopez, O. Lopez, and J. Matas, "On the design of sliding mode control schemes for quantum resonant converters," IEEE Trans. Power Electron., vol. 15, no. 15, pp. 960-973, Nov. 2000.

[22] I. E. Colling and I. Barbi, "Reversible unity power factor step-up/stepdown ac-dc converter controlled by sliding mode," IEEE Trans. Power Electron., vol. 16, no. 2, pp. 223-230, Mar. 2001.

[23] S. K. Mazumder, A. H. Nayfeh, A. Borojevic, P. Gaya, and O. López, "Robust control of parallel dc-dc buck converters by combining integral-variable-structure and multiple-sliding-surface control schemes," IEEE Trans. Power Electron., vol. 17, no. 3, pp. 428-437, May 2002.

[24] S. K. Mazumder, "A novel discrete control strategy for independent stabilization of parallel three-phase boost converters by combining spacevector modulation with variable-structure control," IEEE Trans. Power Electron., vol. 18, no. 4, pp. 1070-1083, Jul. 2003.

[25] H. Sira-Ramirez, "On the generalized PI sliding mode control of DC-to-DC power converters: a tutorial," Int. J. Control, vol. 76, no. 9/10, pp. 1018-1033, 2003.

[26] L. Iannelli and F. Vasca, "Dithering for sliding mode control of dc-dc converters," in Proc. IEEE Power Electron. Spec. Conf. (PESC'04), Jun. 2004, pp. 1616-1620.

[27] S. C. Tan, Y. M. Lai, M. K. H. Cheung, and C. K. Tse, "On the practical design of a sliding mode voltage controlled buck converter," IEEE Trans. Power Electron., vol. 20, no. 2, pp. 425-437, Mar. 2005.

[28] L. Martinez-Salamero, H. Valderrama-Blavi, and R. Giral, "Self-oscillating DC-to-DC switching converters with transformers characteristics," IEEE Trans. Aerosp. Electron. Syst., vol. 41, no. 2, pp. 710-716, Apr. 2005.

[29] S. C. Tan, Y. M. Lai, C. K. Tse, and M. K. H. Cheung, "A fixed-frequency pulse-width-modulation based quasi-sliding mode controller for buck converters," IEEE Trans. Power Electron., vol. 20, no. 6, pp. 1379-1392, Nov. 2005.

[30] S. C. Tan, Y. M. Lai, C. K. Tse, and M. K. H. Cheung, "Adaptive feed-forward and feedback control schemes for sliding mode controlled power converters," IEEE Trans. Power Electron., vol. 21, no. 1, pp. 182-192, Jan. 2006.

[31] E. Vidal-Idiarte, L. Martinez-Salamero, J. Calvente, and A. Romero, "An $H_{\infty}$ control strategy for switching converters in sliding-mode current control," IEEE Trans. Power Electron., vol. 21, no. 2, pp. 553-556, Mar. 2006.

[32] S. C. Tan, Y. M. Lai, C. K. Tse, and C. K. Wu, "A pulsewidth modulation based integral sliding mode current controller for boost converters," in IEEE Power Electron. Spec. Conf. (PESC'06), Jeju, Korea, Jun. 2006, pp. 1612-1618.
[33] J. Knight, S. Shirsavar, and W. Holderbaum, "An improved reliability Cuk based solar inverter with sliding mode control," IEEE Trans. Power Electron., vol. 21, no. 4, pp. 1107-1115, Jul. 2006.

[34] S. C. Tan, Y. M. Lai, and C. K. Tse, "A unified approach to the design of PWM based sliding mode voltage controller for basic DC-DC converters in continuous conduction mode," IEEE Trans. Circuits Syst. I, vol. 53, no. 8, pp. 1816-1827, Aug. 2006.

[35] K. Ogata, Modern Control Engineering. Upper Saddle River, NJ: Prentice-Hall, 1997.

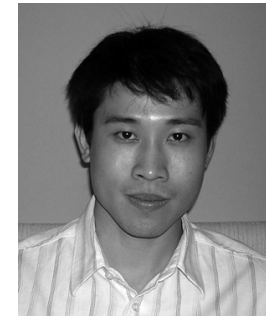

Siew-Chong Tan (S'00-M'06) received the B.Eng. (with honors) and M.Eng. degrees in electrical and computer engineering from the National University of Singapore, Singapore, in 2000 and 2002, respectively, and the Ph.D. degree from the Hong Kong Polytechnic University, Hong Kong, in 2005

He worked briefly as a Research Associate and then a Post-Doctoral Fellow in the Department of Electronic and Information Engineering, Hong Kong Polytechnic University, where he is currently a Lecturer. His research interests include motor drives

and power electronics

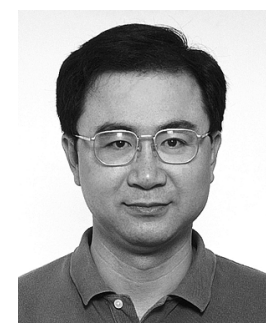

Y. M. Lai (M'92) received the B.Eng. degree in electrical engineering from the University of Western Australia, Perth, Australia, in 1983, the M.Eng.Sc. degree in electrical engineering from University of Sydney, Sydney, Australia, in 1986, and the Ph.D. degree from Brunel University, London, U.K., in 1997.

He is an Assistant Professor with Hong Kong Polytechnic University, Hong Kong. His research interests include computer-aided design of power electronics and non-linear dynamics.

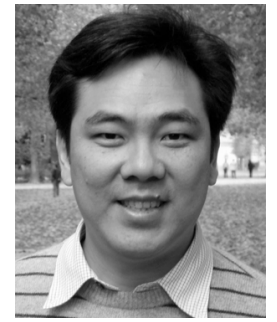

Chi K. Tse (M'90-SM'97-F'06) received the B.Eng. degree (with first-class honors) in electrical engineering in 1987 and the Ph.D. degree in 1991 from the University of Melbourne, Melbourne, Australia.

$\mathrm{He}$ is presently Chair Professor and Head of Department of Electronic and Information Engineering, Hong Kong Polytechnic University, Hunghom, Hong Kong, and is a Guest Professor with Wuhan University, Heibei, China. His research interests include nonlinear systems, complex networks and power electronics. He is the author of Linear Circuit Analysis (London, U.K.: Addison-Wesley, 1998) and Complex Behavior of Switching Power Converters (Boca Raton: CRC Press, 2003), co-author of Chaos-Based Digital Communication Systems (Heidelberg, Germany: Springer-Verlag, 2003), Communications with Chaos (London: Elsevier, 2006) and Signal Reconstruction With Applications to Chaos-Based Communications (Beijing, China: Tsinghua University Press, 2007), and co-holder of a U.S. patent.

Dr. Tse was awarded the L.R. East Prize by the Institution of Engineers, Australia, in 1987. He won the IEEE TRANSACTIONS ON POWER ELECTRONICS Prize Paper Award for 2001 and the International Journal of Circuit Theory and Applications Best Paper Award for 2003. In 2005, he was named an IEEE Distinguished Lecturer. While with Hong Kong Polytechnic University, he twice received the President's Award for Achievement in Research, the Faculty's Best Researcher Award, the Research Grant Achievement Award, and a few other teaching awards. From 1999 to 2001, he served as an Associate Editor for the IEEE TRANSACTIONS ON CIRCUITS AND SYSTEMS PART I-FUNDAMENTAL THEORY AND APPLICATIONS, and since 1999 he has been an Associate Editor for the IEEE TRANSACTIONS ON POWER ELECTRONICS. He currently also serves as the Editor-in-Chief of the IEEE Circuits and Systems Society Newsletter, an Associate Editor for the International Journal of Systems Science, a Guest Associate Editor of the IEICE Transactions on Fundamentals of Electronics, Communications and Computers, and a Guest Editor of Circuits, Systems and Signal Processing. 